\title{
Sistemas de colheita e manejo da palhada de cana-de-açúcar
}

\author{
Zigomar Menezes de Souza(1), Renato de Mello Prado(1), Antônio Claret Strini Paixão(2) e Luiz Gilberto Cesarin ${ }^{(2)}$ \\ (1)Universidade Estadual Paulista, Fac. de Ciências Agrárias e Veterinárias, Dep. de Solos e Adubos, Via de acesso Prof. Paulo Donato \\ Castellane, s/no, CEP 14870-900 Jaboticabal, SP. E-mail: zigomar@fcav.unesp.br, rmprado@fcav.unesp.br (2)Usina Santa Adélia, CEP14870-970 \\ Jaboticabal, SP. E-mail: apaixao@santaadelia.com, Icesarin@santaadelia.com
}

\begin{abstract}
Resumo - A colheita com cana crua está cada vez mais presente no sistema de produção da cana-de-açúcar no Brasil. O objetivo deste trabalho foi avaliar o efeito de sistemas de colheita e manejo da cana crua com e sem incorporação da palhada e cana queimada nos atributos físicos do solo e na produção de colmos em cana-deaçúcar cultivada em um Latossolo Vermelho-Amarelo distrófico. Os tratamentos foram cana-de-açúcar com queima e corte manual; cana-de-açúcar sem queima e corte mecanizado, com incorporação da palha triturada até 0,30 m; e cana-de-açúcar sem queima e corte mecanizado, sem incorporação da palha triturada. Foram determinadas a composição granulométrica, matéria orgânica, estabilidade de agregados, densidade e porosidade do solo nas profundidades de $0,0-0,1,0,1-0,2$ e $0,2-0,3 \mathrm{~m}$ e resistência do solo à penetração e teor de água no solo nas profundidades de $0,0-0,1,0,1-0,2,0,2-0,3$ e $0,3-0,4 \mathrm{~m}$. No sistema de cana crua com incorporação da palhada, a maior produção de colmos foi alcançada, além de maiores valores de matéria orgânica, estabilidade de agregados, macroporosidade e teor de água no solo e menores valores de resistência do solo à penetração e densidade do solo, comparado ao sistema cana crua sem incorporação da palhada e cana queimada.
\end{abstract}

Termos para indexação: Saccharum officinarum, queima da palhada, estabilidade de agregados, densidade do solo, resistência do solo à penetração.

\section{Harvest systems and residue management of sugarcane}

\begin{abstract}
The use of sugarcane harvesting without residue burning is a common harvesting management in Brazil. The objective of this work was to evaluate the effect of harvest systems and management of sugarcane with and without trash incorporation and of burned sugarcane on soil physical attributes as on production of stems in a Red Yellow Latosol (Typic Hapludox). The treatments can be described as sugarcane (Saccharum officinarum) with burning and manual cutting; sugarcane without burning and automated cutting, with incorporation of chopped residue down to $0.30 \mathrm{~m}$; sugarcane without burning and automated cutting, without incorporation of chopped residue. The particle size distribution, soil organic matter, aggregate stability, bulk density and soil porosity in $0.0-0.1,0.1-0.2$ and $0.2-0.3 \mathrm{~m}$ depths were determined as well as soil resistance to penetration and soil moisture in $0.0-0.1,0.1-0.2,0.2-0.3$ and $0.3-0.4 \mathrm{~m}$ depths. The systems sugarcane without burning and sugarcane with residue incorporation revealed the highest stalk production and higher values of organic matter, aggregate stability, macroporosity, water content and smaller values of soil resistance to penetration and bulk density of soil, compared to sugarcane system without incorporation of residue and burned sugarcane.

Index terms: Saccharum officinarum, residue burning, aggregate stability, bulk density, soil resistance to penetration.
\end{abstract}

\section{Introdução}

O tipo de colheita da cana-de-açúcar pode influenciar a produção e longevidade da cultura, os atributos físicos, químicos e biológicos do solo, o meio ambiente e a saúde pública. O sistema de colheita por cana queimada elimina a matéria seca e aumenta a concentração de gás carbônico na atmosfera, contribuindo com o efeito estufa e diminuindo o teor de matéria orgânica no solo. O decreto de Lei Estadual 47.700, de 11 de março de
2003, regulamenta a Lei Estadual 11.241, de 19 de setembro de 2002, que determinou prazos para a eliminação gradativa do emprego do fogo para despalha da cana-de-açúcar nos canaviais paulistas, sendo de grande interesse agrícola e ecológico, estabelecendo prazos, procedimentos, regras e proibições que visam a regulamentar as queimas em práticas agrícolas.

A colheita mecanizada da cana-de-açúcar está cada vez mais presente nos sistemas de produção no Brasil. No sistema de colheita mecanizada sem queima, as fo- 
lhas, bainhas, ponteiro, além de quantidade variável de pedaços de colmo são cortados, triturados e lançados sobre a superfície do solo, formando uma cobertura de resíduo vegetal (mulch) denominada palha ou palhada. A quantidade de palhada de canaviais colhidos sem queima varia de 10 a $30 \mathrm{Mg} \mathrm{ha}^{-1}$ (Trivelin et al., 1996).

A deposição e a manutenção de palhada sobre a superfície do solo, mesmo contribuindo com a sua conservação, pode causar problemas relacionados ao manejo da cultura (Furlani Neto et al., 1997). Entre eles podem ser citados dificuldades durante as operações de cultivo e adubação da soca (Aude et al., 1993), baixa taxa líquida de mineralização de $\mathrm{N}$ no período de um ano agrícola (Trivelin et al., 1995), dificuldade de execução de controle seletivo de plantas daninhas e aumento das populações de pragas que se abrigam e multiplicam sob a palhada (Macedo et al., 2003). Além disso, o grande volume de palha sobre a cana soca dificulta a sua emergência, causando falha na rebrota, especialmente nas variedades melhoradas que foram desenvolvidas num sistema de colheita com queima, que favorecia a maior taxa de emergência da cana soca (Vasconcelos, 2002).

O sistema de cultivo de cana crua foi desenvolvido com a finalidade de eliminar a queima da cultura, a mobilização superficial dos solos e mantê-los cobertos com restos culturais. Nesse sistema, busca-se a redução da erosão e o aumento do teor de matéria orgânica, que provocam a compactação superficial do solo pelo aumento do tráfego de máquinas, ou seja, aumento da densidade do solo e redução de sua porosidade total, a qual poderá restringir o desenvolvimento radicular das culturas (Blair et al., 1998; Blair, 2000; Vasconcelos, 2002).

Vasconcelos (2002), estudando o desenvolvimento do sistema radicular e da parte aérea de socas de cana-deaçúcar sob dois sistemas de colheita, crua mecanizada e queimada manual, verificou que a alteração do sistema de colheita da cana queimada manual para cana crua mecanizada reduz a amplitude térmica do solo, aumenta o teor de água e de matéria orgânica no solo. O elevado tráfego de máquinas e veículos de transbordo causou aumento da densidade do solo até a profundidade de $0,40 \mathrm{~m}$.

O efeito de sistemas de colheita de cana-de-açúcar, especialmente utilizando uma forma intermediária de manejo da cana crua mediante o uso de escarificadores na incorporaração parcial da palhada, e a conseqüente repercussão positiva nos atributos físicos do solo, são pouco conhecidos.
O objetivo deste trabalho foi avaliar o efeito de sistemas de colheita e manejo da cana crua com e sem incorporação da palhada e cana queimada nos atributos físicos e na produção de colmos em cana-de-açúcar cultivada em um Latossolo Vermelho-Amarelo distrófico.

\section{Material e Métodos}

$\mathrm{O}$ experimento foi realizado na área da Usina Santa Adélia, Município de Jaboticabal, SP (2118'67" S, 4811'38" W, $630 \mathrm{~m}$ de altitude). O clima é o mesotérmico de inverno seco (Cwa) pelo critério de classificação climática de Köppen. A área é de topografia plana; o solo foi classificado como Latossolo VermelhoAmarelo distrófico típico álico, textura média A moderado (Embrapa, 1999) (Tabela 1).

Utilizou-se o delineamento experimental de blocos casualizados, com cinco repetições, tendo cada parcela $48 \mathrm{~m}^{2}$. Os sistemas de colheita e manejo da palhada da cana-de-açúcar (Saccharum officinarum), variedade SP 87-0365, foram cana-de-açúcar com queima e corte manual, desde 1973 (cana queimada); cana-de-açúcar sem queima e corte mecanizado com a colhedora (CASE 7700) seguida de transbordo, desde 2000 (cana crua), com incorporação da palha triturada até $0,30 \mathrm{~m}$; e cana-de-açúcar sem queima e corte mecanizado com a colhedora (CASE 7700) seguida de transbordo, desde 2000 (cana crua), sem incorporação da palha triturada. No sistema de colheita com cana crua, a colhedora possui um extrator-triturador de palhiço com a finalidade de diminuir o tamanho dos resíduos. Na cana crua com

Tabela 1. Valores médios $(n=5)$ de argila, silte e areia em três sistemas de colheita e manejo da palhada e três profundidades no Latossolo Vermelho-Amarelo.

\begin{tabular}{lccc}
\hline Sistema de colheita & \multicolumn{3}{c}{ Profundidade $(\mathrm{m})$} \\
\cline { 2 - 4 } & $0,0-0,1$ & $0,1-0,2$ & $0,2-0,3$ \\
\hline & \multicolumn{3}{c}{ Argila $\left(\mathrm{g} \mathrm{kg}^{-1}\right)$} \\
Cana queimada & 270 & 280 & 300 \\
Cana crua com incorporação & 270 & 270 & 300 \\
Cana crua sem incorporação & 260 & 270 & 310 \\
\hline & 40 & Silte $\left(\mathrm{g} \mathrm{kg}^{-1}\right)$ \\
Cana queimada & 30 & 30 & 30 \\
Cana crua com incorporação & 50 & 20 & 30 \\
Cana crua sem incorporação & \multicolumn{3}{c}{ Areia $\left(\mathrm{g} \mathrm{kg}^{-1}\right)$} \\
\hline & 690 & 680 & 670 \\
Cana queimada & 700 & 700 & 670 \\
Cana crua com incorporação & 690 & 710 & 670 \\
Cana crua sem incorporação & 6930
\end{tabular}


incorporação da palhada, utilizou-se escarificador (Modelo Copersucar) com duas hastes Ikeda aladas. $\mathrm{Na}$ operação, usou-se uma haste para cada entre linha da cana-de-açúcar, trabalhando até a profundidade de $0,30 \mathrm{~m}$, promovendo a incorporação da palha em até $70 \%$.

As amostras de solo foram coletadas em outubro de 2003, após a colheita da cana-de-açúcar, nas profundidades de $0,0-0,1,0,1-0,2,0,2-0,3$ e $0,3-0,4 \mathrm{~m}$. Em cada parcela foram coletadas cinco amostras para avaliação dos atributos físicos. Para avaliação da resistência do solo à penetração e teor de água no solo, foram coletadas dez amostras por parcela. $\mathrm{Na}$ análise granulométrica, as amostras deformadas foram passadas em peneira de $2 \mathrm{~mm}$ mediante dispersão com água e $\mathrm{NaOH} 0,1 \mathrm{~mol} \mathrm{~L}^{-1}$ e agitação lenta (16 horas), sendo a argila obtida pelo método da pipeta (Embrapa, 1997). O carbono orgânico foi obtido por oxidação (Embrapa, 1997) e a matéria orgânica, multiplicando-se o carbono orgânico por 1,724. A estabilidade de agregados foi obtida após préumedecimento das amostras com álcool, utilizando as peneiras com abertura de malha de 4,76, 2,00, 1,00, 0,50, 0,25 e $0,125 \mathrm{~mm}$ e agitação lenta por 15 minutos, nas profundidades de $0,0-0,1,0,1-0,2$ e $0,2-0,3 \mathrm{~m}$ (Embrapa, 1997).

Amostras indeformadas foram coletadas com anéis volumétricos de $0,03 \mathrm{~m}$ de altura e $0,048 \mathrm{~m}$ de diâmetro nas profundidades de $0,0-0,1,0,1-0,2$ e $0,2-0,3 \mathrm{~m}$, para determinação da micro e macroporosidade, utilizando a mesa de tensão. A porosidade total foi determinada segundo Embrapa (1997), a microporosidade, por secamento $(0,006 \mathrm{MPa})$ e a macroporosidade, por diferença entre a porosidade total e a microporosidade. A densidade do solo foi determinada segundo Embrapa (1997). A resistência do solo à penetração foi determinada nas profundidades de $0,0-0,1,0,1-0,2,0,2-0,3 \mathrm{e}$ 0,3-0,4 m, com o penetrômetro de impacto (modelo IAA/ Planalsucar-Stolf), com ângulo de cone de $30^{\circ}$ e os resultados transformados segundo Stolf (1991). O teor gravimétrico e volumétrico de água no solo foi obtido segundo Embrapa (1997), nas profundidades de 0,0-0,1, $0,1-0,2,0,2-0,3$ e $0,3-0,4 \mathrm{~m}$.

Nos tratamentos com cana crua após a colheita, determinou-se a massa seca dos resíduos orgânicos da superfície do solo. A produção de colmos de cada parcela foi avaliada mecanicamente no momento da colheita, por meio de uma célula de carga acoplada na carregadeira de cana.
Os dados foram submetidos à análise de variância e as médias comparadas pelo teste de Tukey a 5\% de probabilidade.

\section{Resultados e Discussão}

No tratamento cana queimada, a quantidade de material vegetal deixado na superfície do solo é menor $\left(3 \mathrm{tha}^{-1}\right)$, por um período significativo da cultura da cana-de-açúcar - entre a colheita e o início do fechamento das entre linhas. Nos tratamentos com cana crua com e sem incorporação, foi adicionada maior massa de resíduos orgânicos $\left(12 \mathrm{t} \mathrm{ha}^{-1}\right)$, e no tratamento cana crua com incorporação da palhada, a massa de resíduos orgânicos foi adicionada até aproximadamente $0,30 \mathrm{~m}$ de profundidade, o que permite maior interação entre as frações orgânica e mineral do solo.

O sistema de colheita cana queimada apresentou menores teores de matéria orgânica em relação ao sistema de cana crua, ao passo que o sistema de cana crua com palhada incorporada não diferiu estatisticamente do sistema de cana crua sem incorporação (Tabela 2). Mendonza et al. (2000), em um Podzólico Amarelo, verificaram na profundidade de $0,0-0,1 \mathrm{~m}$, aumento na fração humina e ácidos fúlvicos na matéria orgânica no sistema de cana crua, os quais são importantes na agregação do solo. Os sistemas de cultivo com canade-açúcar e manejo da palhada não diferiram nos teores de matéria orgânica na profundidade de $0,2-0,3 \mathrm{~m}$, corroborando os dados de Mendonza et al. (2000). Os menores teores de matéria orgânica no sistema cana queimada devem-se à queima, realizada antes da colheita, que praticamente elimina a palhada na superfície do solo. No tratamento cana crua, a adição de matéria orgânica na forma de palha (folhas e pontas) foi em média de $12 \mathrm{t} \mathrm{ha}^{-1}$. Segundo Shinitzer (1991), esse material em decomposição origina uma série de compostos orgânicos, como açúcares, aminoácidos, ceras, fenóis, ligninas e ácidos.

A estabilidade de agregados na profundidade de $0,0-0,1 \mathrm{~m}$ foi superior no sistema de cana crua com incorporação da palhada, seguida da cana crua sem incorporação da palhada e cana queimada (Tabela 2). A maior estabilidade de agregados nos sistemas de cana crua com e sem incorporação da palhada deve-se provavelmente ao maior teor de matéria orgânica observado nestes sistemas, concordando com os dados de Tisdall \& Oades (1982), Fuller et al. (1995) e Corrêa (2002). 
O diâmetro médio geométrico (DMG) e diâmetro médio ponderado (DMP) foi superior na cana crua com incorporação da palhada, seguida da cana crua sem incorporação da palhada, comparada à cana queimada. Blair (2000) também verificou DMG superior em 30\% na cana crua, em relação à cana queimada, na profundidade de 0,0-0,1 m, após seis anos de cultivo. Ceddia et al. (1999), em Podzólico Amarelo, verificaram, após cinco anos, maior DMP na cana crua em relação à cana queimada, na profundidade de $0,0-0,05 \mathrm{~m}$, os quais se devem ao maior teor de matéria orgânica.

As modificações da classe de agregados de maior diâmetro (agregados $>2 \mathrm{~mm}$ ) no sistema de cana queimada contribuíram para um maior percentual de agregados na classe entre $1-2 \mathrm{~mm}$ e agregados $<1 \mathrm{~mm}$ (Tabela 2). O mesmo foi constatado por Silva \& Mielniczuk (1997), em sistemas de cultivo em Latossolo Roxo. Segundo Oades (1984), o cultivo intensivo, por favorecer maior taxa de oxidação, resulta na diminuição do teor de matéria orgânica do solo, que proporciona redução na estabilidade dos macroagregados, promovendo, segundo Tisdall \& Oades (1982), o acúmulo de agregados nas classes inferiores a $1 \mathrm{~mm}$ de diâmetro. Alvarenga et al. (1986) verificaram que a manutenção dos restos culturais de milho sobre a superfície do solo favoreceu o desenvolvimento de agregados maiores que $2 \mathrm{~mm}$, em Latossolo.
O DMG, DMP e os agregados $>2 \mathrm{~mm}$ diminuíram enquanto os agregados $<1 \mathrm{~mm}$ aumentaram em profundidade, o que ocorreu também com a matéria orgânica (Tabela 2). Além disso, a maior estabilidade de agregados em superfície ocorreu em virtude da maior concentração de raízes nas camadas superficiais. Nas frações $<1 \mathrm{~mm}$, os maiores valores foram registrados na cana queimada, resultados condizentes com o menor conteúdo de matéria orgânica, o que mostra os efeitos negativos da queimada na estrutura do solo. Os maiores teores de DMG, DMP e agregados na classe $>2 \mathrm{~mm}$ na cana crua com e sem incorporação da palhada, em relação à queimada, decorrem principalmente da permanência de resíduos orgânicos na superfície do solo, os quais se decompõem pela ação de microorganismos, resultando, segundo Shinitzer (1991), na formação de inúmeros compostos na cimentação e estabilização dos agregados. A incorporação da palhada até aproximadamente $0,30 \mathrm{~m}$ provavelmente promove uma melhor atividade da micro, meso e macrofauna do solo (Lima \& Anderson, 1997), permitindo maior interação entre as frações orgânica e mineral do solo com uma maior estabilidade de agregados no sistema de cana crua com incorporação da palha.

O sistema de cana crua com incorporação da palhada diferiu estatisticamente dos demais, apresentando me-

Tabela 2. Valores médios $(n=5)$ da matéria orgânica, diâmetro médio ponderado (DMP), diâmetro médio geométrico (DMG) e tamanho de agregados em três sistemas de colheita e manejo da palhada em três profundidades no Latossolo VermelhoAmarelo(1). $^{(1)}$

\begin{tabular}{|c|c|c|c|c|c|c|}
\hline \multirow[t]{2}{*}{ Sistema de colheita } & \multicolumn{6}{|c|}{ Profundidade $(\mathrm{m})$} \\
\hline & $0,0-0,1$ & $0,1-0,2$ & $0,2-0,3$ & $0,0-0,1$ & $0,1-0,2$ & $0,2-0,3$ \\
\hline & \multicolumn{3}{|c|}{----------Matéria orgânica $\left(\mathrm{g} \mathrm{dm}^{-3}\right)$---------- } & \multicolumn{3}{|c|}{ 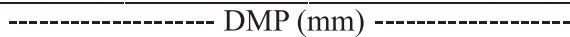 } \\
\hline Cana queimada & $16 \mathrm{Ba}$ & $13 \mathrm{Bb}$ & $10 \mathrm{Ab}$ & $2,43 \mathrm{Ca}$ & $1,69 \mathrm{Cb}$ & $1,30 \mathrm{Bc}$ \\
\hline Cana crua com incorporação & $20 \mathrm{Aa}$ & $17 \mathrm{Ab}$ & $11 \mathrm{Ac}$ & $3,95 \mathrm{Aa}$ & $2,80 \mathrm{Ab}$ & $1,72 \mathrm{Ac}$ \\
\hline Cana crua sem incorporação & $18 \mathrm{Aa}$ & $16 \mathrm{Aa}$ & $11 \mathrm{Ab}$ & $3,18 \mathrm{Ba}$ & $2,03 \mathrm{Bb}$ & $1,25 \mathrm{Bc}$ \\
\hline \multirow[t]{2}{*}{$\mathrm{CV}(\%)$} & \multicolumn{3}{|c|}{6,22} & \multicolumn{3}{|c|}{12,65} \\
\hline & \multicolumn{3}{|c|}{----------------- DMG (mm) ----------------- } & \multicolumn{3}{|c|}{----------- Agregados $>2(\mathrm{~mm})--\cdot-\cdot----$} \\
\hline Cana queimada & $1,33 \mathrm{Ca}$ & $0,91 \mathrm{Cb}$ & $0,60 \mathrm{Bc}$ & $45,79 \mathrm{Ca}$ & $31,45 \mathrm{Cb}$ & $16,54 \mathrm{Bc}$ \\
\hline Cana crua com incorporação & $2,95 \mathrm{Aa}$ & $1,76 \mathrm{Ab}$ & $0,81 \mathrm{Ac}$ & $76,05 \mathrm{Aa}$ & $50,45 \mathrm{Ab}$ & $26,13 \mathrm{Ac}$ \\
\hline Cana crua sem incorporação & $2,40 \mathrm{Ba}$ & $1,14 \mathrm{Bb}$ & $0,40 \mathrm{Cc}$ & $62,01 \mathrm{Ba}$ & $40,33 \mathrm{Bb}$ & $16,55 \mathrm{Bc}$ \\
\hline \multirow[t]{2}{*}{$\mathrm{CV}(\%)$} & \multicolumn{3}{|c|}{10,15} & \multicolumn{3}{|c|}{9,48} \\
\hline & \multicolumn{3}{|c|}{------------Agregados 1-2 (mm)----------- } & \multicolumn{3}{|c|}{------------ Agregados <1 (mm) --------- } \\
\hline Cana queimada & $13,75 \mathrm{Aa}$ & $15,36 \mathrm{Aa}$ & $15,44 \mathrm{Aa}$ & $40,46 \mathrm{Ac}$ & $53,19 \mathrm{Ab}$ & $68,02 \mathrm{Aa}$ \\
\hline Cana crua com incorporação & $7,94 \mathrm{Bb}$ & $11,13 \mathrm{Ba}$ & $15,47 \mathrm{Aa}$ & $16,01 \mathrm{Cc}$ & $38,92 \mathrm{Bb}$ & $58,40 \mathrm{Ba}$ \\
\hline Cana crua sem incorporação & $8,04 \mathrm{Bb}$ & $12,64 \mathrm{Ba}$ & $13,47 \mathrm{Aa}$ & $29,95 \mathrm{Bc}$ & $48,03 \mathrm{Ab}$ & $71,35 \mathrm{Aa}$ \\
\hline CV $(\%)$ & \multicolumn{3}{|c|}{21,23} & \multicolumn{3}{|c|}{19,15} \\
\hline
\end{tabular}

${ }^{(1)}$ Médias seguidas da mesma letra, maiúscula na coluna e minúscula na linha, para a mesma variável, não diferem entre si pelo teste de Tukey a 5\% de probabilidade. 
nores valores em relação à densidade do solo, provavelmente por causa da incorporação da palha até a profundidade de 0,30 $\mathrm{m}$ (Tabela 3). Os sistemas de manejo com cana-de-açúcar aumentaram a densidade do solo até a profundidade de 0,30 m. Hakansson \& Voorhees (1997) também verificaram que sistemas com pouco revolvimento do solo e tráfego de máquinas pesadas promovem compactação do solo até $0,40 \mathrm{~m}$. O aumento da densidade do solo de até $0,30 \mathrm{~m}$ nos sistemas de colheita de cana e manejo da palhada, deve-se ao tráfego de máquinas pesadas durante o plantio e colheita, corroborando os resultados de Flowers \& Lal (1998), quando afirmam que a principal causa da compactação em solos agrícolas é o tráfego de máquinas em operações de preparo do solo, semeadura, tratos culturais e colheita. Silva et al. (2000) constataram que o efeito da diminuição da compactação pode ser anulado por uma única passagem do pneu da colhedora. Os maiores valores de densidade do solo na profundidade de $0,0-0,1 \mathrm{~m}$, na cana crua, são coerentes com o maior tráfego de máquinas na colheita, corroborando os dados de Hartemink (1998). Com a modernização da agricultura, o peso das máquinas e equipamentos assim como a intensidade de uso do solo têm aumentado. Esse processo não foi acompanhado por um aumento proporcional do tamanho e largura dos pneus, resultando em maior risco à compactação do solo e redução da produtividade das culturas (Silva et al., 2000).

A porosidade total e a macroporosidade do solo sob sistema de cana crua com incorporação da palhada foram superiores em todas as profundidades (Tabela 3 ). Esses valores são condizentes com menores valores de densidade do solo e maiores teores de matéria orgânica, pois esta atua na estruturação do solo, confirmando os dados de Cerri et al. (1991). A maior densidade do solo, nas profundidades estudadas, refletiu-se em menor macroporosidade e aumento da microporosidade no sistema de cana crua sem incorporação da palhada comparada à cana queimada.

No sistema com cana crua sem incorporação da palha, verificaram-se os menores valores de macroporosidade do solo, em todas as profundidades, menor até mesmo que $10 \%$, mínimo valor de porosidade de aeração necessário ao desenvolvimento do sistema radicular (Gupta \& Allmaras, 1987). Neste contexto, Carvalho et al. (1991) afirmam que a macroporosidade é o atributo físico mais afetado pelo cultivo contínuo de cana-de-açúcar. O fato de a superfície do solo no sistema de cana queimada ficar exposta aos impactos das gotas de chuva, principalmente no período pós-colheita, que coincide com as maiores taxas de precipitações pluviais mensais (outubro a janeiro), pode ter contribuído no aumento da densidade do solo e microporosidade e na diminuição da porosidade total e da macroporosidade.

O sistema de cana crua com incorporação da palhada novamente diferiu estatisticamente dos demais, apresentando menores valores para a resistência do solo à penetração, provavelmente por causa da incorporação da palha até $0,30 \mathrm{~m}$ (Tabela 4). Independentemente do sistema de colheita de cana-de-açúcar, houve aumento da resistência do solo à penetração até $0,30 \mathrm{~m}$, confirmando os dados de Silva et al. (2000), que avaliaram a resistência mecânica do solo à penetração pelo tráfego de uma colhedora em dois sistemas de manejo do solo em um Latossolo Vermelho. Houve aumento da resistência à penetração da profundidade de $0,1-0,2 \mathrm{~m}$ para 0,3-0,4 m, com valores considerados restritivos ao desenvolvimento radicular. Arshad et al. (1996) afirmam

Tabela 3. Valores médios $(n=5)$ de densidade do solo, porosidade total, macro e microporosidade em três sistemas de colheita e manejo da palhada e três profundidades no Latossolo Vermelho-Amarelo ${ }^{(1)}$.

\begin{tabular}{|c|c|c|c|c|c|c|}
\hline \multirow[t]{2}{*}{ Sistema de colheita } & \multicolumn{6}{|c|}{ Profundidade $(\mathrm{m})$} \\
\hline & $0,0-0,1$ & $0,1-0,2$ & $0,2-0,3$ & $0,0-0,1$ & $0,1-0,2$ & $0,2-0,3$ \\
\hline & \multicolumn{3}{|c|}{------Densidade do solo $\left(\mathrm{m}^{3} \mathrm{~m}^{-3}\right)$------ } & \multicolumn{3}{|c|}{ - Porosidade total $\left(\mathrm{m}^{3} \mathrm{~m}^{-3}\right)$} \\
\hline Cana queimada & $1,50 \mathrm{Bb}$ & $1,52 \mathrm{Bb}$ & $1,58 \mathrm{Aa}$ & $0,42 \mathrm{Ba}$ & $0,40 \mathrm{Ba}$ & $0,39 \mathrm{Aa}$ \\
\hline Cana crua com incorporação & $1,40 \mathrm{Cb}$ & $1,42 \mathrm{Cb}$ & $1,50 \mathrm{Ba}$ & $0,49 \mathrm{Aa}$ & $0,47 \mathrm{Aab}$ & $0,45 \mathrm{Ab}$ \\
\hline Cana crua sem incorporação & $1,60 \mathrm{Aa}$ & $1,58 \mathrm{Aa}$ & $1,62 \mathrm{Aa}$ & $0,40 \mathrm{Ba}$ & $0,38 \mathrm{Bab}$ & $0,36 \mathrm{Ab}$ \\
\hline \multirow[t]{2}{*}{ CV (\%) } & \multicolumn{3}{|c|}{4,75} & \multicolumn{3}{|c|}{6,45} \\
\hline & \multicolumn{3}{|c|}{------Macroporosidade $\left(\mathrm{m}^{3} \mathrm{~m}^{-3}\right)^{-------}$} & \multicolumn{3}{|c|}{------ Microporosidade $\left(\mathrm{m}^{3} \mathrm{~m}^{-3}\right)^{---}$} \\
\hline Cana queimada & $0,15 \mathrm{Ba}$ & $0,17 \mathrm{Aa}$ & $0,11 \mathrm{Ab}$ & $0,32 \mathrm{Bb}$ & $0,36 \mathrm{Ba}$ & $0,37 \mathrm{Ba}$ \\
\hline Cana crua com incorporação & $0,20 \mathrm{Aa}$ & 0,19 Aa & $0,10 \mathrm{Ab}$ & $0,27 \mathrm{Ca}$ & $0,27 \mathrm{Ca}$ & $0,32 \mathrm{Ca}$ \\
\hline Cana crua sem incorporação & $0,08 \mathrm{Ca}$ & $0,08 \mathrm{Ba}$ & $0,06 \mathrm{Ba}$ & $0,37 \mathrm{Ab}$ & $0,41 \mathrm{Aa}$ & $0,44 \mathrm{Aa}$ \\
\hline $\mathrm{CV}(\%)$ & \multicolumn{3}{|c|}{9,78} & \multicolumn{3}{|c|}{8,24} \\
\hline
\end{tabular}

${ }^{(1)}$ Médias seguidas da mesma letra, maiúscula na coluna e minúscula na linha, para a mesma variável, não diferem entre si pelo teste de Tukey a 5\% de probabilidade. 
que valores entre 2,0 e 4,0 MPa dificultam o desenvolvimento radicular das culturas.

A resistência do solo à penetração é inversamente proporcional ao teor de água no solo (Imhoff et al., 2001). Assim, pode-se inferir que, se os três sistemas registrassem o mesmo teor de água no solo, a cana crua apresentaria valores superiores à cana queimada. Mas, como as determinações foram realizadas na mesma data, deve-se inicialmente destacar o efeito dos restos culturais sobre a estrutura do solo e, conseqüentemente, o maior teor de água no solo. Na cana crua com e sem incorporação da palhada, verifica-se maior retenção de água comparada à cana queimada, em que ocorre menor infiltração de água e maiores valores de densidade e matéria orgânica no solo.

O sistema com cana crua e incorporação da palhada apresentou maior produção de colmos, quando comparado com o sistema de cana sem incorporação da palhada e cana queimada (Tabela 5). Este efeito superior da cana crua com incorporação na produção de colmos é explicado pelos efeitos positivos deste sistema nos atributos

Tabela 4. Valores médios $(\mathrm{n}=10)$ de resistência do solo à penetração, umidade gravimétrica e volumétrica em três sistemas de colheita e manejo da palhada e quatro profundidades no Latossolo Vermelho-Amarelo ${ }^{(1)}$.

\begin{tabular}{lcccc}
\hline Sistema de colheita & \multicolumn{4}{c}{ Profundidade $(\mathrm{m})$} \\
\cline { 2 - 5 } & $0,0-0,1$ & $0,1-0,2$ & $0,2-0,3$ & $0,3-0,4$ \\
\hline \multirow{4}{*}{ Resistência do solo à penetração $(\mathrm{MPa})$} \\
Cana queimada & $1,10 \mathrm{Bd}$ & $1,39 \mathrm{Bc}$ & $2,58 \mathrm{Ab}$ & $2,81 \mathrm{Aa}$ \\
Cana crua com incorporação & $0,75 \mathrm{Cc}$ & $0,96 \mathrm{Cc}$ & $1,45 \mathrm{Cb}$ & $2,30 \mathrm{Ca}$ \\
Cana crua sem incorporação & $1,15 \mathrm{Bd}$ & $1,63 \mathrm{Ac}$ & $2,27 \mathrm{Bb}$ & $2,50 \mathrm{Ba}$ \\
\hline & Teor gravimétrico de água no solo $\left(\mathrm{kg} \mathrm{kg}^{-1}\right)$ \\
Cana queimada & $0,10 \mathrm{Bb}$ & $0,12 \mathrm{Ba}$ & $0,11 \mathrm{Ba}$ & $0,13 \mathrm{Aa}$ \\
Cana crua com incorporação & $0,16 \mathrm{Aa}$ & $0,15 \mathrm{Aa}$ & $0,15 \mathrm{Aa}$ & $0,15 \mathrm{Aa}$ \\
Cana crua sem incorporação & $0,15 \mathrm{Aa}$ & $0,14 \mathrm{Aa}$ & $0,14 \mathrm{Aa}$ & $0,14 \mathrm{Aa}$ \\
\hline & Teor volumétrico de água no solo $\left(\mathrm{m}^{3} \mathrm{~m}^{-3}\right)$ \\
Cana queimada & $0,17 \mathrm{Ba}$ & $0,18 \mathrm{Ba}$ & $0,16 \mathrm{Ba}$ & $0,17 \mathrm{Ba}$ \\
Cana crua com incorporação & $0,23 \mathrm{Aa}$ & $0,24 \mathrm{Aa}$ & $0,23 \mathrm{Aa}$ & $0,22 \mathrm{Aa}$ \\
Cana crua sem incorporação & $0,26 \mathrm{Aa}$ & $0,22 \mathrm{Ab}$ & $0,22 \mathrm{Ab}$ & $0,21 \mathrm{Ab}$ \\
\hline
\end{tabular}

${ }^{(1)}$ Médias seguidas da mesma letra, maiúscula na coluna e minúscula na linha, quanto a mesma variável, não diferem entre si pelo teste de Tukey a $5 \%$ de probabilidade; os coeficientes de variação em relação à resistência do solo à penetração, teor gravimétrico e volumétrico de água no solo foram de $23,75 \%, 6,19 \%$ e $7,12 \%$, respectivamente.

Tabela 5. Produção da cana-de-açúcar em diferentes sistemas de colheita e manejo da palhada ${ }^{(1)}$.

\begin{tabular}{lc}
\hline Sistema de colheita & Colmos $\left(\mathrm{t} \mathrm{ha}^{-1}\right)$ \\
\hline Cana queimada & $137,13 \mathrm{a}$ \\
Cana crua com incorporação da palhada & $156,15 \mathrm{~b}$ \\
Cana crua sem incorporação da palhada & $134,19 \mathrm{a}$ \\
\hline
\end{tabular}

${ }^{(1)}$ Médias seguidas da mesma letra não diferem entre si pelo teste de Tukey a $5 \%$ de probabilidade. físicos do solo, como discutido anteriormente. Wood (1991) e Mcyntere et al. (1996) encontraram efeito positivo da palhada sobre a produtividade da cultura de cana-de-açúcar. Por outro lado, Aude et al. (1993) verificaram que a cobertura do solo por palhada de cana-de-açúcar teve efeito negativo na produtividade. Ball-Coelho et al. (1993), em solo tropical, observaram que a manutenção da palhada sobre o solo causou aumento de $43 \%$ na produção de matéria seca da cana-de-açúcar.

Ao se considerar que a cana crua apresentou valores superiores de densidade do solo e que este sistema de colheita está aumentando progressivamente, é importante intensificar os estudos com suporte de carga desses solos, para evitar excessiva compactação do solo. Lal (2000) afirma que a adoção de sistemas com a manutenção de resíduos na superfície, como o sistema de cana crua, é fundamental para a redução da degradação do solo e do meio ambiente, em solos tropicais. Dias et al. (2001), em um estudo sobre agroeconomia de sistemas de preparo do solo, em área de colheita mecanizada de cana crua em latossolo, observaram que o sistema reduzido com incorporação da palha com aiveca mostrou-se um sistema de manejo promissor.

\section{Conclusões}

1. Os sistemas de colheita de cana-de-açúcar alteraram os atributos físicos do solo até a profundidade de $0,30 \mathrm{~m}$.

2. O sistema de cana crua com incorporação da palhada proporciona maior produção de colmos, maiores teores de matéria orgânica, maior estabilidade de agregados, macroporosidade e teor de água e menores valores de resistência do solo à penetração e densidade do solo, quando comparado ao sistema cana crua sem incorporação da palhada e cana queimada.

3. O sistema de colheita de cana-de-açúcar sem queima e com incorporação parcial dos resíduos culturais melhoram as condições físicas do solo e aumentam o potencial produtivo da cana-de-açúcar.

\section{Agradecimentos}

À Fundação de Amparo à Pesquisa do Estado de São Paulo (Fapesp), pela concessão de bolsa de estudo a Zigomar Menezes de Souza; à Usina Santa Adélia, pela permissão de realização do experimento em sua área experimental. 


\section{Referências}

ALVARENGA, R.C.; FERNANDES, B.; SILVA, T.C.A.; REZENDE, M. Estabilidade de agregados de um Latossolo sob diferentes métodos de preparo do solo e de manejo da palha do milho. Revista Brasileira de Ciência do Solo, v.10, p.273-277, 1986.

ARSHAD, M.A.; LOWERY, B.; GROSSMAN, B. Physical tests for monitoring soil quality. In: DORAN, J.W.; JONES, A.J. Methods for assessing soil quality. Madison: Soil Science Society of America, 1996. p.123-141. (SSSA Special publication, 49).

AUDE, M.I.S.; MARCHEZAN, P.L.; DARIVA, T.; PIGNATARO, L.H.B. Manejo do palhiço da cana-de-açúcar: efeito na produção de colmos industrializáveis e outras características agronômicas. Ciência Rural, v.23, p.281-286, 1993.

BALL-COELHO, B.; TIESSEN, H.; STEWART, J.W.B.; SALCEDO, I.H.; SAMPAIO, V.S.B. Residue management effects on sugarcane yield and soil properties in Northeastern Brazil. Agronomy Journal, v.85, p.1004-1008, 1993.

BLAIR, G.J.; CHAPMAN, L.; WHITBREAD, A.M.; BALLCOELHO, B.; LARSEN, P.; TIESSEN, H. Soil carbon changes resulting from sugarcane trash management at two locations in Queensland, Australia, and in North-East Brazil. Australian Journal of Soil Research, v.36, p.873-882, 1998.

BLAIR, N. Impact of cultivation and sugar-cane green trash management on carbon fractions and aggregate stability for a Chromic Luvisol in Queensland, Australia. Soil \& Tillage Research, v.55, p.183191, 2000.

CARVALHO, S.R.; BRUAND, A.; HARDY, M.; LEPRUM, J.C.; JAMAGNE, M. Tassement des sols ferrallitiques Podzólico Vermelho Amarelo sous culture de canne à sucre (état de Rio de Janeiro, Brézil): apport d'une analyse de la porosité associée a une connaissance détaillée de la phase minérale. Cahiers ORSTOM Série Pedologie, v.26, p.195-212, 1991.

CEDDIA, M.B.; ANJOS, L.H.C.; LIMA, E.; RAVELLI NETO, A.; SILVA, L.A. Sistemas de colheita da cana-de-açúcar e alterações nas propriedades físicas de um solo Podzólico Amarelo no Estado do Espírito Santo. Pesquisa Agropecuária Brasileira, v.34, p.14671473, 1999.

CERRI, C.C.; FELLER, C.; CHAUVEL, A. Evolução das principais propriedades de um Latossolo Vermelho-Escuro após desmatamento e cultivo por doze e cinqüenta anos com cana-de-açúcar. Cahiers ORSTOM Série Pedologie, v.26, p.37-50, 1991.

CORRÊA, J.C. Efeito de sistemas de cultivo na estabilidade de agregados de um Latossolo Vermelho-Amarelo em Querência, MT. Pesquisa Agropecuária Brasileira, v.37, p.203-209, 2002.

DIAS, F.L.F.; CASAGRANDE, A.A.; CAMPOS, M.S.; ANDRIOLI, I. Estudo agroeconômico de sistemas de preparo do solo, em área de colheita mecanizada de cana crua. Stab - Açúcar, Álcool e Subprodutos, v.20, p.26-29, 2001.

EMBRAPA. Centro Nacional de Pesquisa de Solos (Rio de Janeiro, RJ). Manual de métodos de análise de solo. 2.ed. Rio de Janeiro, 1997. 212p. (Documentos, 1).
EMBRAPA. Centro Nacional de Pesquisa de Solos (Rio de Janeiro, RJ). Sistema brasileiro de classificação de solos. Brasília: Embrapa-SPI/Embrapa-CNPS, 1999. 412p.

FLOWERS, M.D.; LAL, R. Axle load and tillage effects on soil physical properties and soybean grain yield on a mollic ochraqualf in northwest Ohio. Soil \& Tillage Research, v.48, p.21-35, 1998.

FULLER, L.G.; GOH, T.G.; OSCARSON, D.W. Cultivation effects on dispersive clay of soil aggregates. Canadian Journal of Soil Science, v.75, p.101-107, 1995.

FURLANI NETO, V.L.; RIPOLI, T.C.; VILA NOVA, N.A. Biomassa de cana-de-açúcar: energia contida no palhiço remanescente de colheita mecânica. Stab-Açúcar, Álcool e Subprodutos, v.15, p.24-27, 1997.

GUPTA, S.C.; ALLMARAS, R.R. Models to assess the susceptibility of soils to excessive compaction. Advances in Soil Science, v.6, p.65-100, 1987.

HAKANSSON, I.; VOORHEES, W.B. Soil compaction. In: LAL, R.; BLUM, W.H.; VALENTIN, C. (Ed.). Methods for assessment of soil degradation. Boca Raton: Lewis, 1997. p.167-179.

HARTEMINK, A.E. Soil chemical and physical properties as indicators of sustainable land management under sugar cane in Papua New Guinea. Geoderma, v.85, p.283-306, 1998.

IMHOFF, S.; SILVA, A.P.; DIAS JUNIOR, M.S.; TORMENA, C.A. Quantificação de pressões críticas para o crescimento das plantas. Revista Brasileira de Ciência do Solo, v.25, p.11-18, 2001.

LAL, R. Soil management in the developing countries. Soil Science, v.165, p.57-72, 2000.

LIMA, J.M.; ANDERSON, S.J. Aggregation and aggregates size effects on extractable iron and aluminum in two Hapludoxs. Soil Science Society of America Journal, v.61, p.965-970, 1997.

MACEDO, N.M.; BOTELHO, P.S.M.; CAMPOS, M.B.S. Controle químico de cigarinha-da-raiz em cana-de-açúcar e impacto sobre a população de artrópodes. Stab - Açúcar, Álcool e Subprodutos, v.21, p.30-33, 2003.

MENDONZA, H.N.S.; LIMA E.; ANJOS, L.H.C.; SILVA, L.A.; CEDDIA, M.B.; ANTUNES, M.V.M. Propriedades químicas e biológicas de solo de tabuleiro cultivado com cana-de-açúcar com e sem queima da palhada. Revista Brasileira de Ciência do Solo, v.24, p.201-207, 2000.

MCYNTERE, G.; SERUTTUN, S.; BARBE, C. Trash management in Marutian sugarcane plantations. In: INTERNATIONAL SOCIETY OF SUGAR CANE TECHNOLOGIST, 22., 1995, Cartagena. Proceedings. Cali, 1996. v.2, p.213-216.

OADES, J.M. Soil organic matter and structural stability: mechanisms and implications for management. Plant and Soil, v.76, p.319337, 1984.

SHINITZER, M. Soil organic matter: the next 75 years. Soil Science, v.151, p.41-58, 1991.

SILVA, I.F.; MIELNICZUK, J. Ação do sistema radicular de plantas na formação e estabilização de agregados do solo. Revista Brasileira de Ciência do Solo, v.21, p.113-117, 1997.

SILVA, V.R.; REINERT, D.J.; REICHERT, J.M. Resistência mecânica do solo à penetração influenciada pelo tráfego de uma colhedora em dois sistemas de manejo do solo. Ciência Rural, v.30, p.795-801, 2000. 
STOLF, R. Teoria e teste experimental de fórmulas de transformação dos dados de penetrômetro de impacto em resistência do solo. Revista Brasileira de Ciência do Solo, v.15, p.229-235, 1991.

TISDALL, J.M.; OADES, J.M. Organic matter and water-stable aggregates is soils. Journal of Soil Science, v.33, p.141-163, 1982.

TRIVELIN, P.C.O.; VICTORIA, R.L.; RODRIGUES, J.C.S. Aproveitamento por soqueira de cana-de-açúcar de final de safra do nitrogênio da aquamônia- ${ }^{-15} \mathrm{~N}$ e uréia- ${ }^{15} \mathrm{~N}$ aplicado ao solo em complemento à vinhaça. Pesquisa Agropecuária Brasileira, v.30, p.1375-1385, 1995.

TRIVELIN, P.C.O.; RODRIGUÊS, J.C.S.; VICTORIA, R.L.; REICHARDT, K. Utilização por soqueira de cana-de-açúcar de início de safra do nitrogênio da aquamônia- $-{ }^{15} \mathrm{~N}$ e uréia- ${ }^{15} \mathrm{~N}$ aplicado ao solo em complemento a vinhaça. Pesquisa Agropecuária Brasileira, v.31, p.89-99, 1996.

VASCONCELOS, A.C.M. Desenvolvimento do sistema radicular da parte aérea de socas de cana-de-açúcar sob dois sistemas de colheita: crua mecanizada e queimada manual. 2002. 140p. Tese (Doutorado) - Universidade Estadual Paulista, Jaboticabal.

WOOD, A.W. Management of crop residues following green harvesting of sugarcane in north Queensland. Soil \& Tillage Research, v.20, p.69-85, 1991.

Recebido em 29 de abril de 2004 e aprovado em 13 de setembro de 2004 